\title{
DO CUME AO INCÔMODO AMENIZADO NA ESCALA DE AVALIAÇÃO DO ENADE: ESTUDO DAS CAUSAS CRÍTICAS NO CURSO DE CIÊNCIAS CONTÁBEIS DA UNIR/PORTO VELHO-RO, NOS TRIÊNIOS 2004/06 E 2007/09
}

\author{
Jean Marcos da Silva * \\ José Moreira da Silva Neto *** \\ Gleimíria Batista da Costa *** \\ Adelmo Pedro Oliveira Júnior *****
}

\begin{abstract}
Resumo
A preocupação com a eficiência dos profissionais de áreas diversificadas, entre estas a contábil, teve como uma das consequências a criação e implantação do Exame Nacional de Desempenho de Estudantes (ENADE). A partir deste, é possível verificar qual área de conhecimento não está atingindo a suficiência esperada pelos discentes das instituições de ensino superior. Assim, na avaliação do ENADE em relação ao curso de Ciências Contábeis da Universidade Federal de Rondônia (UNIR) nos triênios 2004/06 e 2007/09, a Instituição obteve notas 05 e 03, respectivamente, numa escala em que 01 é o conceito crítico e 05 , o conceito máximo. Neste contexto, o presente artigo procurou identificar quais variáveis foram determinantes para a queda de conceito do curso de Ciências Contábeis da UNIR. A pesquisa é relevante, pois, através dos achados e das conclusões, os gestores do curso poderão elaborar estratégias orientadas por estas a fim de minimizar as variáveis que ocasionaram a redução do conceito mencionado. A pesquisa foi exploratório-descritiva, com abordagem qualitativa, por meio de estudo documental. Conclui-se que tal redução ocorreu devido (i) às diferenças mínimas de notas entre estudantes concluintes e ingressantes; (ii) à redução brusca no percentual de acerto dos estudantes concluintes no relatório do triênio 2004/06 e triênio 2007/09 em conhecimento específico; (iii) à equivalência de conhecimento geral entre concluintes da Instituição e ingressantes do Brasil.
\end{abstract}

Palavras-chave: Conceito ENADE. Ciências Contábeis/UNIR. Ingressantes e concluintes.

\footnotetext{
* Bacharel em Ciências Contábeis. Assistente de Gestão em Defesa Agropecuária na Agência de Defesa Sanitária Agrosilvopastoril do Estado de Rondônia. Membro do Grupo de Pesquisas Centro de Estudos Interdisciplinar para o Desenvolvimento Sustentável da Amazônia - CEDSA. E-mail: jean_msnmarcos@hotmail.com.

** Doutor em Ciências Contábeis pela Universidade de São Paulo - USP. Professor Titular de Ciências Contábeis na Universidade Federal de Rondônia. E-mail: dasilvanetojm@gmail.com.

*** Doutora em Desenvolvimento Regional. Professora do Curso de Ciências Contábeis da Universidade Federal de Rondônia - UNIR. E-mail: gleimiria@unir.br.

***** Mestre em Administração. Professor Assistente do Curso de Ciências Contábeis da Universidade Federal de Rondônia.E-mail: adelmopedrojunior@uol.com.br.
} 


\section{Introdução}

A Universidade Federal de Rondônia (UNIR) é uma instituição de ensino superior pública e gratuita, localiza-se na cidade de Porto Velho, capital do Estado de Rondônia e forma profissionais para atuar em várias áreas do conhecimento. Entre os cursos oferecidos pela instituição, tem-se o de Ciências Contábeis, oferecido em três campi: Vilhena, Cacoal e Porto Velho.

Neste contexto, a argumentação de que não é suficiente formar bacharéis em Ciências Contábeis já está consolidada no mercado de trabalho. É preciso ir além, observando se tais contadores/contabilistas formados atendem ao mínimo de conhecimento requerido para a atuação profissional exigida. Considerando esta e outras preocupações, o Ministério da Educação (MEC) implantou o Sistema Nacional de Avaliação da Educação Superior (SINAES), cujo objetivo é avaliar as Instituições de Ensino Superior (IES). Dentre os integrantes do SINAES, destaca-se o Exame Nacional de Desempenho de Estudantes (ENADE), responsável por medir o desempenho dos discentes desde o ingresso até a conclusão do curso.

Assim sendo, a UNIR também passa por processos avaliativos dos cursos disponibilizados pela Instituição. A cada três anos consecutivos, os estudantes ingressantes e concluintes realizam uma prova de conhecimento geral e específico, o ENADE, para fins de verificação do desempenho de tais discentes. Dentre os objetivos, tem-se o de observar se o estudante concluinte adquiriu, ao longo dos quatro anos de curso, conhecimentos determinantes para uma significativa atuação no mercado de trabalho.

Ao concluir a avaliação, é disponibilizado no relatório trienal do ENADE um quadro contendo uma classificação do curso em uma escala que varia de 01 a 05 , em que 01 é a situação crítica e 05, o conceito mais elevado. Nas duas últimas avaliações, triênios 2004/06 e 2007/09, a UNIR obteve notas de certo modo distantes entre si. No penúltimo triênio a Universidade recebeu nota 05, enquanto que na última avaliação o conceito caiu para 03 - uma redução brusca de um período para o outro. Considerando tal fato, este artigo abordou a seguinte problemática: quais as variáveis determinantes para a queda de conceito do curso de Ciências Contábeis da Universidade Federal de Rondônia?

Como objetivo geral destaca-se: verificar as variáveis que influenciaram na redução de conceito do curso de Ciências 
Contábeis, de 05 pontos para 03 pontos. Ao buscar atingir o objetivo geral mencionado, delinearam-se os seguintes objetivos específicos: (i) destacar as informações mais relevantes dos dois últimos relatórios do ENADE; (ii) confrontar os dados disponíveis no relatório do triênio 2004/06 com os dispostos no do triênio 2007/09; (iii) identificar o desempenho dos alunos concluintes em relação aos ingressantes no que se refere aos diversos quesitos avaliados pelo ENADE. A figura a seguir representa graficamente a diferença no conceito mencionado de acordo com dados do triênio 2004/2006 e 2007/09.

Figura 1 - Conceito do curso de Ciências Contábeis da Universidade Federal de Rondônia, campus Porto Velho

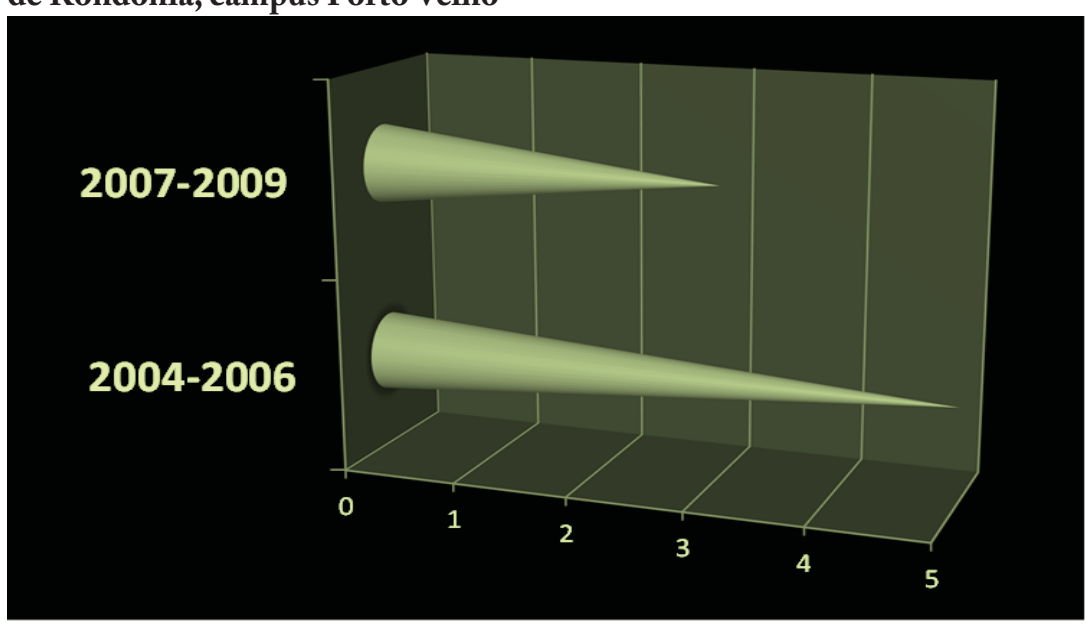

Fonte: elaboração dos autores com base em MEC/INEP/DAES-ENADE.

Quanto aos objetivos, este artigo enquadra-se como exploratório e descritivo. Isto porque a intenção foi realizar análises aprofundadas dos dados apresentados pelo ENADE, com o intuito de verificar quais variáveis foram determinantes para a diferença de conceito de um triênio para o outro. Além disso, optou-se pela pesquisa descritiva, que, de acordo com Gil (1999), ela consiste em descrever as características de determinada população, bem como relacionar variáveis.

Em relação à abordagem do problema, este estudo é qualitativo, uma vez que faz uso da análise dos dados constantes nos relatórios ENADE dos triênios 2004/06 e 2007/09. Já no que se refere aos procedimentos, trata-se de um estudo documental. Isto porque se utiliza de fontes secundárias por meio de documentos relacionados ao ENADE. Neste sentido, 
Gil (1999) argumenta que a pesquisa documental baseia-se em materiais que ainda não receberam tratamento ou que possam ser trabalhados novamente.

Os procedimentos de coleta de dados ocorreram com base nos relatórios elaborados pelo INEP, disponíveis no endereço eletrônico do instituto, no link "Relatório do Curso e IES". Desta forma, procedeu-se à seleção dos relatórios de avaliação do curso de Ciências Contábeis da UNIR no triênio 2007/09, no qual 22 ingressantes e 38 concluintes realizaram a prova, e no triênio 2004/06, em que 23 concluintes e 26 ingressantes se apresentaram para a avaliação.

Para responder tal problemática, o artigo está organizado nas seguintes partes: perfil socioeconômico dos discentes ingressantes e concluintes; domínio dos professores para ministrar as aulas; metodologia utilizada e conclusões contidas no relatório do ENADE sobre o curso de Ciências ContábeisUNIR; diferenças observadas entre os relatórios dos triênios 2004/06 e 2007/09; e, finalmente, questões da prova ENADE com menor percentual de acerto entre os estudantes concluintes. Além disso, na sequencia, disponibilizam-se os resultados e as conclusões da pesquisa.

\section{Contextualizando o Exame Nacional de Desempenho de Estudantes}

A "Década da Educação" no Brasil foi instituída a partir da publicação da Lei das Diretrizes e Bases da Educação Nacional (LDB), Lei n. 9.394, de 20 de dezembro de 1996, que no seu Art. $3^{\circ}$, Item IX apregoa como princípio a "garantia de padrão de qualidade" do ensino. Para aquilatar esse padrão de qualidade, estabelecem-se processos de avaliação (PAIVA, 2008).

O Ministério da Educação criou o Sistema Nacional de Avaliação da Educação Superior (SINAES) com o objetivo de avaliar as Instituições de Ensino Superior (IES), os cursos de graduação e o desenvolvimento dos estudantes. O ENADE, integrante do SINAES, mede o rendimento da aprendizagem dos estudantes desde seu ingresso até a conclusão do curso. Dentre os cursos avaliados, destaca-se o de Ciências Contábeis, isto porque o profissional desta área necessita construir habilidades e desenvolver competências fundamentais para auxiliar na gestão das organizações. 
Pela Lei n. 10.861/04, de 14 de abril de 2004, instituiuse o Sistema Nacional de Avaliação da Educação SuperiorSINAES. Segundo o INEP (2009), o SINAES veio para "assegurar processo nacional de avaliação das instituições de educação superior, dos cursos de graduação e do desempenho acadêmico de seus estudantes”. Esse sistema avalia a instituição, o curso, os coordenadores e professores dos cursos e o desempenho dos estudantes ingressantes e concluintes através do ENADE.

O ENADE consiste em uma prova para o aluno, questionário de avaliação discente da educação superior (ADES), questionário dos coordenadores de curso e a percepção do aluno sobre a prova. Desse modo, o ENADE visa medir o potencial de aprendizagem dos alunos ingressantes e as competências profissionais adquiridas em sua trajetória pela instituição que cursou. Ainda, segundo o Instituto Nacional de Estudos e Pesquisas Educacionais Anísio Teixeira (2009), o ENADE tem por objetivo:

[...] avaliar o desempenho dos estudantes com relação aos conteúdos programáticos previstos nas diretrizes curriculares dos cursos de graduação, o desenvolvimento de competências e habilidades necessárias ao aprofundamento da formação geral e profissional, e o nível de atualização dos estudantes com relação à realidade brasileira e mundial, integrando o SINAES, juntamente com a avaliação institucional e a avaliação dos cursos de graduação.

Os resultados do ENADE devem apresentar um diagnóstico quanto a (a) conhecimentos, habilidades e competências adquiridas pelos estudantes no curso de graduação, (b) verificação da capacidade de leitura e interpretação de textos, (c) análise crítica das informações e, (d) nas situações apresentadas, estabelecimento de relações e comparações.

Nas áreas e cursos a serem avaliados pelo ENADE, consideram-se ingressantes os estudantes que se encontram no final do primeiro ano, que, no prazo estipulado pela legislação pertinente a este exame, tenham cumprido entre $7 \%$ e $22 \%$ da carga horária mínima do currículo do curso. Concluintes são os que estão cursando o último ano, isto é, os que cumpriram até a data inicial do período de inscrição pelo menos $80 \%$ da carga horária mínima do currículo do curso, bem como aqueles que tenham condições de concluir o curso durante o ano letivo no qual será realizado o exame da área (INEP, 2009). 


\section{Análise dos dados}

\section{Perfil socioeconômico dos estudantes ingressantes e concluintes e percepção em relação à UNIR}

Os dados da avaliação do ENADE, referentes a dois triênios - 2004/6 e 2007/9 -foram utilizados como base para responder a problemática da pesquisa. $\mathrm{O}$ questionário enviado pelo ENADE ao estudante em datas anteriores à aplicação das provas mencionadas deveria ser entregue no momento de realização destas. Essa ferramenta permite o conhecimento do perfil socioeconômico dos estudantes ingressantes e concluintes, bem como a sua percepção em relação à Universidade. A Figura 2 demonstra a origem dos estudantes.

Figura 2 - Declaração de Cor/Raça segundo os /triênios 2004/6 e 2007/9

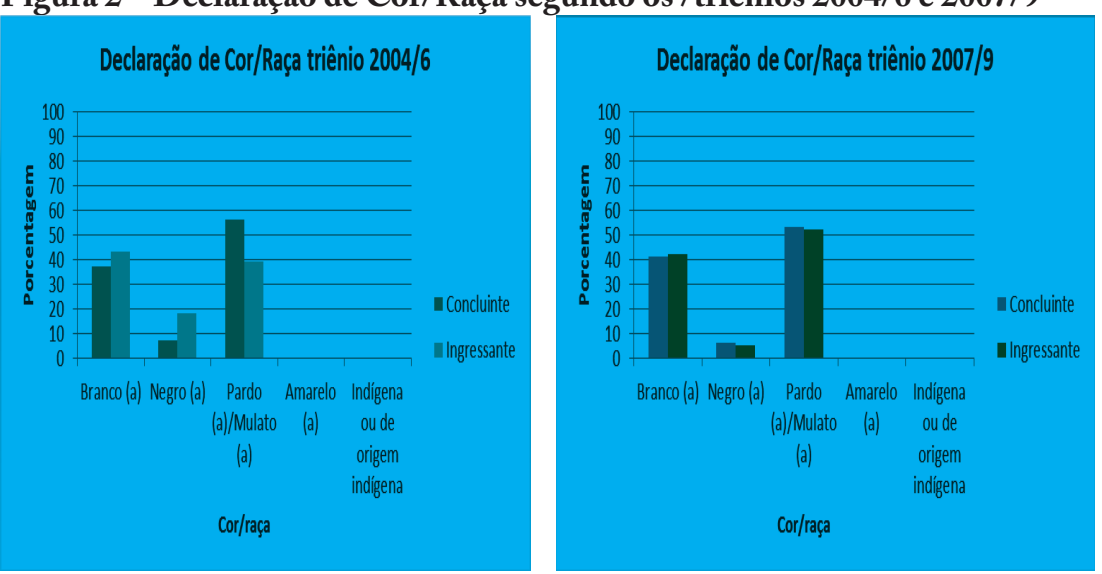

Fonte: adaptado pelos autores (MEC/INEP/DAES-ENADE, 2012).

Ao observar a figura 2, nota-se que no triênio 2004/6 havia uma baixa representação de negros no curso de Ciências Contábeis. Apesar de no triênio 2007/9 a sua participação não ter crescido de forma expressiva, percebe-se uma determinada evolução. Quanto às instalações físicas da Universidade, no triênio 2004/06, a maior parte dos concluintes que pensam do mesmo modo, cerca de $40 \%$, afirmaram ser adequadas, pois são amplas, arejadas, bem iluminadas e com mobiliário sofisticado. Já os ingressantes deste citado triênio não pensam da mesma maneira, pois a maioria dos que assinalaram a mesma alternativa, cerca de $35 \%$, percebem as salas como malarejadas, mal-iluminadas, com o imobiliário inadequado e pequenas em relação ao número de estudantes. 
A situação torna-se mais preocupante nos anos que sucedem a publicação deste material. O relatório ENADE do triênio seguinte-2007/9 aponta que somente algumas poucas condições físicas da Universidade são adequadas. Se no triênio anterior a avaliação apontou discordância de opinião entre ingressantes e concluintes, no mais recente relatório, as opiniões de ambos os grupos de estudantes se equipararam. O principal diferencial agora está no fato de as opiniões serem basicamente unânimes entre os dois grupos de estudantes.

Outro ponto avaliado pelo ENADE foi se os professores, na visão dos acadêmicos ingressantes e concluintes, possuíam domínio das disciplinas ministradas. No triênio 2004/6, uma pequena parcela dos ingressantes, aproximadamente $10 \%$, disseram que todos os professores possuíam total domínio na matéria lecionada, enquanto que nenhum dos concluintes afirmou isso - estes, ao contrário, preferiram deduzir que menos da metade dos docentes da UNIR possuíam domínio da disciplina ministrada.

Neste sentido, na avaliação do triênio 2006/9, tanto os ingressantes quanto os concluintes assinalaram que a maior parte dos docentes apresenta domínio das disciplinas ministradas. A figura 3 demonstra a percepção dos acadêmicos em relação ao domínio dos professores para ministrar as disciplinas no triênio 2006/9.

Figura 3 - Domínio dos professores para ministrar as disciplinas

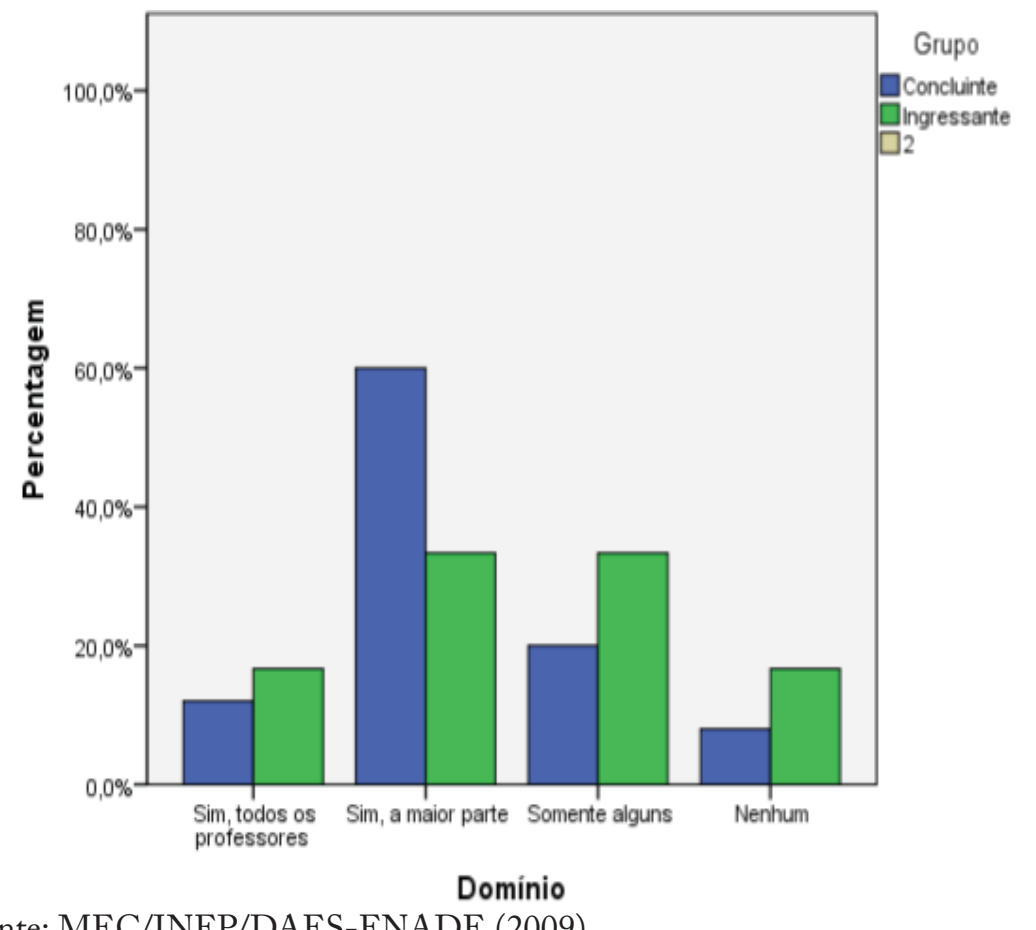

Fonte: MEC/INEP/DAES-ENADE (2009). 
Os rendimentos das famílias e dos estudantes ingressantes e concluintes foram identificados para fins de classificação de perfil econômico dos discentes do curso de Ciências Contábeis da UNIR/Porto Velho, Rondônia.

Figura 4 - Renda Familiar por ingressante e concluinte, triênio 2007/9

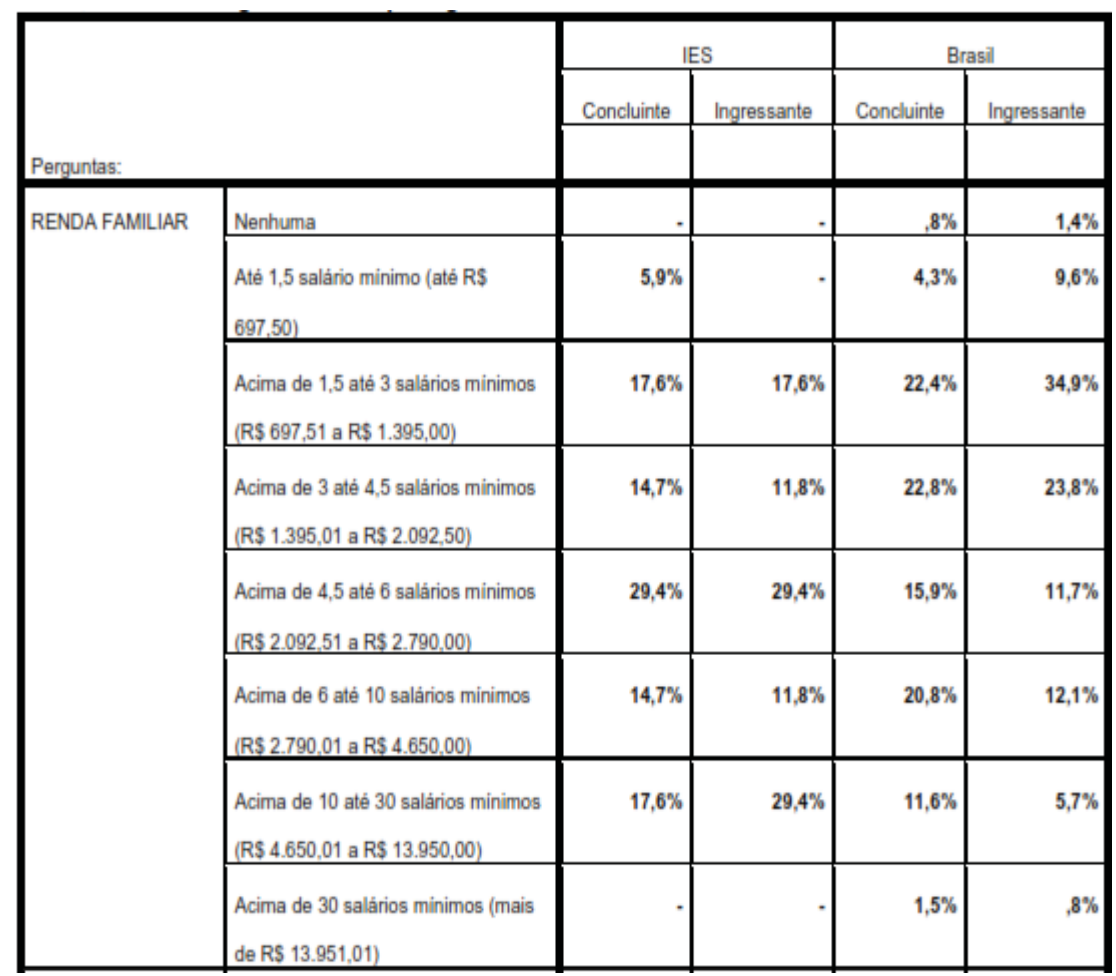

Fonte: MEC/INEP/DAES-ENADE (2009).

A figura 4 apresenta um resumo da renda auferida pelas famílias dos discentes no triênio 2006/9. Percebe-se que aproximadamente $61 \%$ dos discentes, tanto ingressante quanto concluintes, possuem uma renda familiar acima $\mathrm{R} \$ 2.000,00$. Já no triênio 2004/6, 80\% dos estudantes ingressantes e concluintes encontravam-se com renda familiar abaixo de $\mathrm{R} \$ 3.500,00$. Um dado curioso ocorre quando se analisa o percentual de renda familiar apenas dos concluintes: destes, aproximadamente 36\%, número bastante expressivo, possuíam renda abaixo de $\mathrm{R} \$$ 1.050,00 no triênio 2004/6; no outro extremo, pouco menos de $30 \%$ dos acadêmicos ingressantes do triênio 2006/9 auferiam renda entre $R \$ 4.600,00$ e $R \$ 13.000,00$. Conclui-se que o curso de Ciências Contábeis em análise atraiu, de um período para o outro, pessoas de classe econômica mais elevada. $\mathrm{Na}$ figura 5, a seguir, observa-se a renda dos discentes no triênio 2004/6. 
Figura 5 - Faixa de renda mensal familiar dos discentes, triênio 2004/6

\begin{tabular}{|c|c|c|c|c|c|c|c|}
\hline \multirow[b]{2}{*}{ Questão } & \multirow[b]{2}{*}{ Itens } & \multicolumn{3}{|c|}{ Ingressantes } & \multicolumn{3}{|c|}{ Concluintes } \\
\hline & & $\begin{array}{l}\text { Nota } \\
\text { média }\end{array}$ & $\begin{array}{l}\text { Desvio } \\
\text { padrão }\end{array}$ & $\%$ & $\begin{array}{c}\text { Nota } \\
\text { média }\end{array}$ & $\begin{array}{l}\text { Desvio } \\
\text { padrão }\end{array}$ & $\%$ \\
\hline \multirow{7}{*}{$\begin{array}{l}\text { Faixa } \\
\text { de } \\
\text { renda } \\
\text { mensal } \\
\text { da sua } \\
\text { família }\end{array}$} & $\begin{array}{l}\text { Até } 3 \text { salários } \\
\text { mínimos (até } R \$ \\
1.050,00) \text {. }\end{array}$ & 37,4 & 11,6 & 16,7 & 43,9 & 10,1 & 36,4 \\
\hline & $\begin{array}{l}\text { De } 3 \text { até } 5 \\
\text { salários mínimos } \\
(\mathrm{R} \$ 1.051,00 \text { até } \\
1.750,00) .\end{array}$ & 42,1 & 8,8 & 29,2 & 46,9 & 4,5 & 13,6 \\
\hline & $\begin{array}{l}\text { De } 5 \text { até } 10 \\
\text { salários mínimos } \\
(\mathrm{R} \$ 1.751,00 \text { até } \\
\mathrm{R} \$ 3.500,00) .\end{array}$ & 44,2 & 6,9 & 33,3 & 48,2 & 6,3 & 18,2 \\
\hline & $\begin{array}{l}\text { De } 10 \text { até } 15 \\
\text { salários mínimos } \\
(\mathrm{R} \$ 3.151,00 \text { até } \\
\mathrm{R} \$ 5.250,00) .\end{array}$ & 51,9 & 0,0 & 4,2 & 43,6 & 2,6 & 18,2 \\
\hline & $\begin{array}{l}\text { De } 15 \text { salários } \\
\text { mínimos até } 24 \\
\text { salários mínimos } \\
\text { (R\$ } 5.291,00 \text { até } \\
\mathrm{R} \$ 7.000,00) \text {. }\end{array}$ & 41,7 & 0,6 & 8,3 & 28,3 & 0,0 & 4,5 \\
\hline & $\begin{array}{l}\text { De } 24 \text { salários } \\
\text { mínimos até } 34 \\
\text { salários mínimos } \\
(\mathrm{R} \$ 7.001,00 \text { até } \\
\mathrm{R} \$ 10.500,00) \text {. }\end{array}$ & 42,5 & 2,5 & 8,3 & 45,9 & 2,9 & 9,1 \\
\hline & $\begin{array}{l}\text { Mais de } 34 \\
\text { salários mínimos } \\
\text { (mais de } R \$ \\
10.500,00 \text { ). }\end{array}$ & - & - & - & - & - & - \\
\hline
\end{tabular}

Fonte: MEC/INEP/DAES-ENADE (2006).

Metodologia utilizada e conclusões contidas nos relatórios do Exame Nacional de Desempenho de Estudantes (ENADE) sobre o curso de Ciências Contábeis da UNIR em Porto Velho

A nota atribuída pelo ENADE ao curso de Ciências Contábeis da UNIR segue uma determinada metodologia. Consistiu, basicamente, em dividir a prova em partes, destinando pesos a estas de acordo com a área de conhecimento correspondente. Assim, na avaliação do último triênio, o conhecimento específico correspondia a $75 \%$ da nota final, enquanto o conhecimento geral 
correspondia a $25 \%$. Do mesmo modo procedeu-se na avaliação do triênio 2004/6.

O diferencial existente entre os dois triênios está no fato de no mais antigo considerar-se as seguintes variáveis: o desempenho dos estudantes concluintes e ingressantes no componente específico, o desempenho dos estudantes concluintes e ingressantes no componente de conhecimentos gerais. Já no triênio 2006/9, consideraram-se apenas as notas obtidas pelos concluintes nos conhecimentos específico e geral. Todas as fórmulas utilizadas para o cômputo da nota estão expressas no relatório final de cada área, disponível na internet. Enfim, chega-se ao conceito do ENADE para os triênios tratados nesta pesquisa: para o triênio 2004/6, tem-se conceito 05; para o triênio 2007/9, tem-se conceito 03. Isto em uma escala de 01 a 05 , em que 01 é considerado baixo e 05, o mais elevado.

Ao observar-se a avaliação do relatório do triênio 2007/9, tem-se que 22 ingressantes compareceram e 38 concluintes realizaram a prova. Em contrapartida, no relatório do triênio 2004/6, havia 23 concluintes e 26 ingressantes. A figura 6 apresenta um comparativo das notas obtidas pelos estudantes da UNIR com as obtidas pelos estudantes do Brasil em matéria de conhecimento geral. Observa-se que, na média dos concluintes da UNIR e dos ingressantes do Brasil, constataram-se basicamente as mesmas notas. Situação esta preocupante, porque se deduz que a instituição não contribuiu para a formação de conhecimento geral dos estudantes.

Figura 6 - Comparativo de notas entre ingressantes e concluintes UNIR e Brasil na formação geral triênio 2007/9

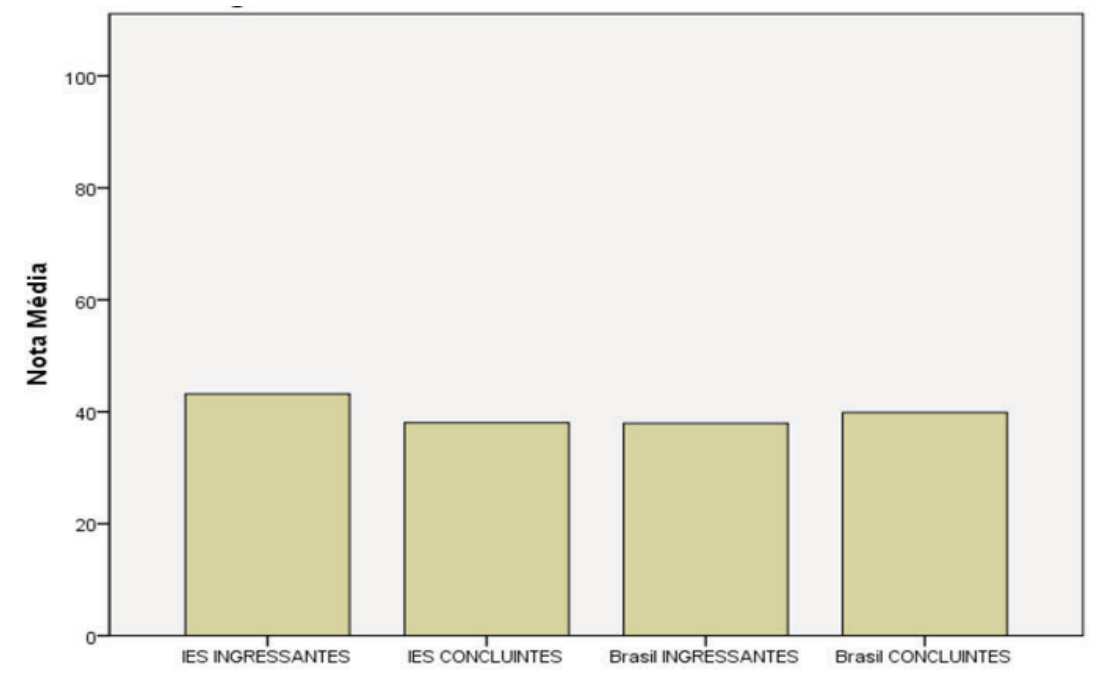

Fonte: MEC/INEP/DAES-ENADE (2009). 
$\mathrm{Na}$ sequência, apresentam-se informações de mesma natureza, mas referentes ao triênio 2004/6. Percebe-se na figura 7 que a UNIR possui notas acima da média nacional em ambos os grupos de estudantes, tanto ingressantes quanto concluintes.

Figura 7. Comparativo de notas entre ingressantes e concluintes UNIR e Brasil na formação geral triênio 2004/6

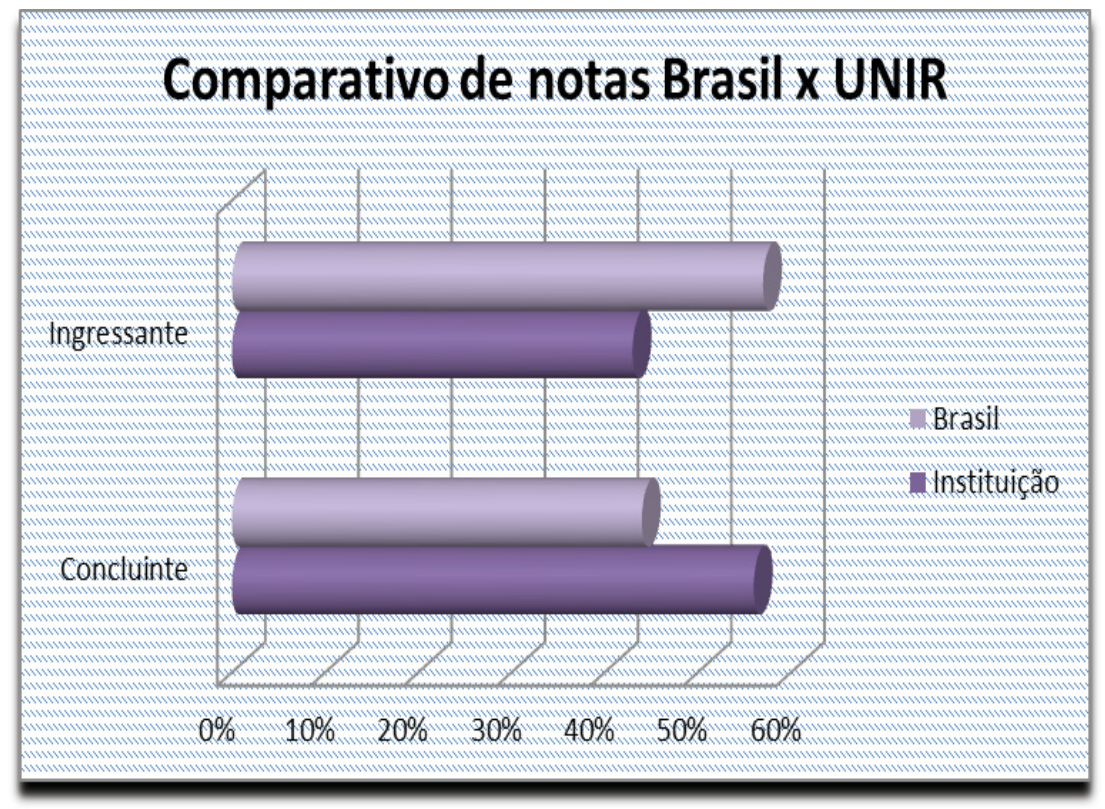

Fonte: MEC/INEP/DAES-ENADE (2009).

Quanto ao conhecimento específico, houve uma queda brusca nas notas de um relatório para o outro em relação aos discentes concluintes. $\mathrm{Na}$ avaliação do triênio 2004/6, os ingressantes obtiveram 30,2\%, alcançando 30,6\% no triênio seguinte. Houve uma elevação nas notas. $\mathrm{O}$ mesmo não se repete quando se trata dos estudantes concluintes, para os quais se verifica uma queda brusca na pontuação. $O$ fato de ter havido maior número de participantes concluintes, de 23 para 38 estudantes, não afetou positivamente as notas deste grupo de estudantes. Eles alcançaram nota equivalente a 31,1 no triênio $2007 / 9$ e nota 37,2 no triênio $2004 / 9$.

No quadro a seguir, apresentamos os conteúdos das questões com o menor percentual de acerto dos estudantes concluintes visando elencar quais deles incidiram negativamente na avaliação do curso. 
Quadro 1 - Conteúdos das questões ENADE 2006 e 2009 com o menor percentual de acertos entre os concluintes da UNIR

\begin{tabular}{|c|c|l|c|}
\hline Ano & $\begin{array}{c}\text { Questão } \\
\left(\mathrm{n}^{\circ}\right)\end{array}$ & \multicolumn{1}{|c|}{ Assunto Abordado } & $\begin{array}{c}\% \text { de } \\
\text { acerto }\end{array}$ \\
\hline \multirow{2}{*}{2006} & 13 & Reconhecimento de Passivo Exigível & 17,4 \\
\cline { 2 - 4 } & 25 & $\begin{array}{l}\text { Contabilidade de Custos-Custeio por } \\
\text { Absorção }\end{array}$ & 0,0 \\
\hline \multirow{2}{*}{2009} & 16 & $\begin{array}{l}\text { Métodos de Depreciação que não o } \\
\text { Linear }\end{array}$ & 10,5 \\
\cline { 2 - 4 } & 21 & Consolidação de Balanços Contábeis & 13,2 \\
\hline
\end{tabular}

Fonte: elaborado pelos autores (2010).

A situação crítica da prova aplicada em 2006 está relacionada ao conhecimento de contabilidade de custos. Nesta questão, sequer um dos 23 estudantes concluintes em 2006 assinalou a resposta correta. Já em 2009, a atenção se volta para a questão de número 16, referente aos métodos de depreciação. $\mathrm{O}$ método cobrado na prova não era o linear, sendo este o mais enfatizado nas disciplinas ministradas, por este motivo, o percentual de acerto foi um dos menores.

\section{Considerações finais}

De modo geral, a avaliação realizada com a aplicação do ENADE apontou uma variedade de percentuais com intuito de evidenciar as variáveis determinantes na atribuição das notas para o curso de Ciências Contábeis da UNIR/Porto Velho/Rondônia. Para o triênio 2004/6, tem-se conceito 05; e para o triênio 2007/9, o conceito 03. Isto em uma escala de 01 a 05 , em que 01 é considerado baixo e 05, o mais elevado.

De acordo com o perfil socioeconômico dos acadêmicos do curso, percebe-se que pertencem, cada vez mais, a classes sociais com maior poder aquisitivo. No que diz respeito aos concluintes, este dado está relacionado a mudanças ocorridas no cenário contábil e à valorização deste profissional. Entre os ingressantes, nota-se, na UNIR, um número crescente de acadêmicos do sexo feminino. Apesar de ainda a cor branca/parda ser maioria entre os estudantes pesquisados, houve aumento de participantes negros nas cadeiras da Universidade.

Considerando tal quadro e tendo em vista buscar respostas à problemática delimitada - Quais as variáveis determinantes para a queda de conceito do curso de Ciências Contábeis da 
Universidade Federal de Rondônia? -, conclui-se que os números indicaram três relevantes questões: (i) as diferenças mínimas de notas entre estudantes concluintes e ingressantes, pois a Instituição perde prestígio uma vez que o concluinte, neste caso, após passar pelas cadeiras da Universidade, não possui seus conhecimentos afetados de maneira significativa; (ii) a redução brusca no percentual de acerto dos estudantes concluintes no relatório do triênio 2004/6 (37,2) e triênio 2007/9 $(31,1)$ em conhecimento específico, que corresponde a $75 \%$ do conceito final do ENADE; (iii) a equivalência de conhecimento geral entre concluintes da Instituição e ingressantes do Brasil. Tal situação deve ser considerada preocupante, já que existem ingressantes no Brasil com os mesmos conhecimentos gerais dos concluintes formados pela UNIR, isto porque o conhecimento geral contribui com os $25 \%$ restantes para a composição do conceito ENADE. Outra questão é a percepção diferenciada entre os estudantes, de forma geral, em se tratando de infraestrutura, pois, ao responderem o questionário socioeconômico, afirmaram que as condições físicas se depreciaram ao longo dos dois triênios.

\section{Referências}

GIL, Antônio Carlos. Métodos e técnicas de pesquisa social. 5. ed. São Paulo: Atlas, 1999.

INEP - Instituto Nacional de Estudos e Pesquisas Educacionais Anísio Teixeira. Disponível em: <http://www. inep.gov.br/superior/enade/ enade_oquee.htm>.Acesso em: 29 abr. 2011.

ENADE 2009: perguntas frequentes. Disponível em: <http:// www.inep.gov.br/superior/enade/ perguntas_frequentes.htm>. Acesso em: 29 out. 2011.

ENADE 2006: relatório de cursos e IES. Disponível em: <http://enade2006.inep.gov.br/novo/Site/?c=CUniversidade\&m=verJis tagem_ies_pdf.> Acesso em: 23 out. 2011.

: relatório síntese. Disponível em: <http://www.inep.gov. br/download/enade/2006/relatorios/Ciencias_Contabeis_RelatorioFinal.pdf.> Acesso em: 26 out. 2011.

PAIVA, Giovanni Silva. Avaliação do desempenho dos estudantes da educação superior: a questão da equidade e obrigatoriedade no provão e Enade. Ensaio, v. 58, n. 16, p. 31-46, 2008. 


\title{
DO CUME AO INCOMODO AMENIZADO IN SCALE EVALUATION ENADE: CRITICAL STUDY OF CAUSES IN ACCOUNTING COURSE OF UNIR/PORTO VELHO-RO, THE TRIENNIUM 2004/06 AND 2007/09
}

\begin{abstract}
The concern with the efficiency of professionals in different areas, among them the book, had as a consequence the creation and implementation of the National Survey of Student Performance (NSSP). From the same you can see which area of knowledge is not reaching the expected sufficiency by students of higher education institutions. Thus, in evaluating the ENADE over the course of Accountancy at the Federal University of Rondônia (UNIR) in triennium 2004/06 and 2007/09, the company obtained notes 5:03, respectively, on a scale where 01 is the critical concept and 05 the maximum concept. In this context, this article aims to identify which variables were instrumental in the fall of concept Accounting course of UNIR. The research is important because through the findings and conclusions, travel managers can develop strategies guided by these findings in order to minimize the variables that led to the reduction of the concept mentioned. We conclude that this reduction was due to: (i) minimum differences in grades between students and conclusive entrant, (ii) the sharp reduction in the percentage of correct students graduating in the three year report 2004/06 triennium and 2007/09 into knowledge specific, (iii) the equivalence of knowledge among graduates of the institution and entering Brazil. The research was exploratory, descriptive, qualitative approach, through documentary study.
\end{abstract}

Keywords: Concept ENADE. Accounting / UNIR. Newcomer and Conclusive 